\title{
Financiación y costo de capital de un proyecto industrial en una empresa peruana
}

Augusto Cáceres Rosell

Ingeniero industrial por la Universidad de Lima. Máster en Administración de Negocios por la Escuela de Administración de Negocios para Graduados (ESAN). Consultor de negocios. Profesor de la Universidad de Lima.

Este artículo muestra la importancia de determinar la mejor combinación de financiación de un proyecto. El autor analiza el costo del capital de la empresa comparándolo con la tasa financiera de rendimiento, definiendo así el costo de capital como la tasa mínima de rentabilidad; también revisa la evaluación de fuentes de financiamiento sobre la base de dividendos, aplicándola a un caso práctico en una empresa industrial. 


\section{Introducción}

La función financiera puede dividirse en tres importantes áreas presentes en toda empresa: decisiones en materia de inversión, de financiamiento y de pago de dividendos. Cada una de ellas debe estudiarse teniendo en cuenta el objetivo básico de la empresa. Sólo una combinación óptima de esos tres tipos de inversiones permitirá elevar al máximo el valor que tiene una empresa para sus accionistas.

Las decisiones de financiamiento consisten en determinar la mejor combinación de fuentes financieras o estructura de financiamiento. Si es posible modificar el valor de mercado de una empresa variando su estructura de financiamiento, entonces debe existir alguna estructura óptima que maximice el precio de mercado de sus acciones. La decisión de financiamiento debe considerar la composición de los activos, la actual y la prevista para el futuro, porque ella determina la naturaleza del riesgo empresarial, tal como es percibida por los inversores; y a su vez esa percepción de riesgo empresarial afecta al costo real de las distintas fuentes de financiación.

\section{Objetivo}

Invertir consiste en renunciar al gasto o consumo de unos bienes en el momento actual para aplicarlos a otros fines con la esperanza de obtener en el futuro mayores beneficios. Con esta decisión se espera recuperar la propia inversión más unos fondos adicionales, cuyos excedentes constituyen el rendimiento.

Financiar significa dotar de recursos económicos suficientes para solucionar todas las necesidades creadas por una inversión o gasto corriente. La financiación se puede efectuar a través de capital o reservas, denominadas recursos propios, o a través de deudas. El objetivo principal de este caso es evaluar las diferentes alternativas de financiamiento que tiene la empresa para desarrollar un gran proyecto regional. Entre las alternativas para la financiación están los diversos bancos internacionales, así como una entidad crediticia nacional, además de contar con el dinero depositado en diferentes bancos del continente. Además de determinar en qué proporción y cantidad de dinero le conviene a la empresa endeudarse, tiene como objetivos calcular el costo de capital. 


\section{Marco teórico}

La decisión de inversión está directamente relacionada con la financiación, porque la aceptación o rechazo de un proyecto depende de la forma en que se le financie.

La tasa de corte es la pauta que nos sirve para evaluar la conveniencia económica de una inversión. Esta tasa, por lo común, es igual al costo del capital para la empresa, y recordamos que se emplea para la aceptación de proyectos cuando se cumple que la tasa financiera de rendimiento de un proyecto es mayor que la tasa de costo de capital.

El costo de capital representa una tasa de corte para la asignación de fondos a los proyectos de inversión; en teoría, debe ser igual a la tasa financiera de rendimiento de los proyectos, que permitiría mantener invariable el valor de las acciones. En este sentido, el costo de capital es la tasa mínima de rentabilidad necesaria para que se justifique el uso de los fondos.

El costo de financiamiento puede ser definido como la tasa de rendimiento sobre proyectos de inversión que es necesaria para mantener invariable la cotización de las acciones de la empresa. Cada empresa tiene a su disposición un vasto surtido de métodos de financiamiento, cada uno de ellos con un costo explícito. Utilizando un modelo de valuación sobre la base de dividendos, el costo del capital propio es la tasa de descuento que iguala el valor actual de la corriente de dividendos futuros esperados, según es concebida por los inversores marginales, con la cotización del mercado de la acción.

Una vez medido el costo de cada método de financiamiento, puede calcularse un costo medio ponderado de financiamiento o costo medio del capital. La base de ponderación empleada debería corresponder a las proporciones de cada fuente que la empresa entiende utilizar. Una vez computado, el costo medio ponderado se utiliza como base para la aceptación o rechazo de los proyectos de inversión.

En teoría la empresa debería determinar su óptima estructura de financiamiento y financiar sus futuros proyectos de inversión en las proporciones requeridas. La estructura óptima de financiamiento es aquella en que el costo marginal real de todos los métodos de financiación posibles es el mismo, entendiendo por costo real la suma de todos los costos, tanto explícitos como implícitos. 


\section{Autofinanciación}

Se denomina autofinanciación a los fondos que permanecen en la empresa, y que han sido generados en ésta, fruto de su propia actividad económica.

Cuando todos los recursos de la empresa están constituidos por fondos propios, la autofinanciación se mide en función de su capacidad de autofinanciación del período que se está estudiando, en relación con los fondos propios.

Un aspecto que se debe tener en cuenta es que, en gran medida, la autofinanciación, en cuanto a su volumen, estará muy condicionada por la política de dividendos. Es decir, cuanto mayor sea la retribución del dividendo efectivo del período, más reducida será la cantidad destinada a la autofinanciación. En cambio, cuanto menor sea la dotación de efectivo para dividendos, mayor será la autofinanciación.

\section{Endeudamiento}

Una deuda en una empresa incrementa sus obligaciones, aportando un riesgo que debe ser analizado y cuantificado.

\section{Aplicación práctica}

Una empresa industrial peruana requiere US $\$ 3$ millones para un proyecto regional. Esta empresa tiene las siguientes alternativas de financiamiento a través de la banca internacional:

\begin{tabular}{lcc}
\hline Nombre del banco & $\begin{array}{c}\text { Monto o } \\
\text { importe US\$ }\end{array}$ & $\begin{array}{c}\text { Tasa de interés } \\
\text { anual \% }\end{array}$ \\
\hline Chase Manhattan & 900.000 & 10 \\
City Bank & 600.000 & 9 \\
Bank of Tokio & 300.000 & 9 \\
Bank Boston & 150.000 & 10 \\
Atlantic Security Bank & 150.000 & 9 \\
\hline
\end{tabular}

Además, la empresa tiene depositados US $\$ 1,5$ millones en diferentes bancos del continente por los que recibe en promedio una tasa de interés pasiva del $6 \%$ anual. 
Por último, existe una entidad financiera nacional dispuesta a prestar nuevos soles por el equivalente a S/.1,5 millones a un costo de $2,0 \%$ mensual.

¿En qué proporciones y cantidades le conviene a esta empresa endeudarse? Calcular el costo de capital estimado.

\section{Solución}

\section{Proporción de endeudamiento}

De acuerdo con los datos presentados en el caso, tomando en cuenta las tasas de interés de los bancos, llegamos a la conclusión de que a la empresa le conviene endeudarse en la siguiente proporción y cantidad:

\begin{tabular}{lcc}
\hline Nombre del banco & $\begin{array}{c}\text { Monto } \\
\text { miles US\$ }\end{array}$ & $\begin{array}{c}\text { Porcentaje (\%) } \\
\text { deuda total }\end{array}$ \\
\hline Chase Manhattan & 450 & 30 \\
City Bank & 600 & 40 \\
Bank of Tokio & 300 & 20 \\
Atlantic Security Bank & 150 & 10 \\
Total & 1.500 & 100 \\
\hline
\end{tabular}

Considerando que el City Bank, el Bank of Tokio y el Atlantic Security Bank tienen como tasa de interés efectiva anual 9\%, mientras que el Chase Manhattan y el Bank Boston tienen una tasa de interés efectiva anual de 10\%, elegimos las opciones de menor costo, y completamos el monto de la deuda con el Chase Manhattan, dejando de lado en esta oportunidad al Bank Boston, debido a que esta última entidad bancaria estaría dispuesta a prestar solamente 150 mil dólares.

Se descartó a la entidad financiera nacional dispuesta a prestar un monto equivalente a 1,5 millones de dólares, debido a que ofrecía un interés muy elevado, de 2,0\% mensual, lo cual es equivalente a una tasa de interés efectiva anual de $27 \%$, tasa mayor que el interés de la banca internacional.

Aún teniendo en cuenta la devaluación promedio de los últimos cuatro años, equivalente a $10,2 \%$, las tasas de interés internacionales son menores que las nacionales. 


\section{Devaluación}

\begin{tabular}{ccccc}
\hline Año & 1995 & 1996 & 1997 & 1998 \\
\hline$\%$ & 8,67 & 10,66 & 5,70 & 15,66 \\
\hline
\end{tabular}

Además se está considerando que el 50\% del financiamiento, es decir, 1,5 millones de dólares son por capital propio, que la empresa tiene depositados en diferentes bancos del continente.

\section{Costo de capital ponderado}

El costo de capital ponderado lo calculamos de acuerdo con el efecto de la relación Deuda $=50 \%$ y Capital propio $=50 \%$ en el costo de capital:

\begin{tabular}{|c|c|c|c|c|c|c|}
\hline \multicolumn{4}{|c|}{ Deuda \% } & \multicolumn{2}{|c|}{ Capital propio \% } & Costo de capital \% \\
\hline (1) $35 \%$ & 9 & (2) $15 \%$ & 10 & $50 \%$ & 6 & - \\
\hline \multirow[t]{2}{*}{3,15} & + & 1,50 & & & & - \\
\hline & 4,65 & & & + & 3,00 & 7,65 \\
\hline
\end{tabular}

(1)

$\begin{array}{ll}\text { City Bank } & 40 \% \\ \text { Bank of Tokio } & 20 \% \\ \text { Atlantic Security Bank } & 10 \% \\ & 50 \% \times 70 \%=35 \% \\ \text { (2) } & \\ \text { Chase Manhattan } & 30 \% \\ & 50 \% \times 30 \%=15 \%\end{array}$

Por lo tanto, el costo de capital ponderado es igual a 7,65\%. Tomando en cuenta que el 50\% del financiamiento está constituido por la deuda, de la cual el 35\% tiene una tasa de interés de $9 \%$ y el $15 \%$ una tasa de interés de $10 \%$. Mientras que el otro $50 \%$ del financiamiento está constituido por el capital propio que recibe en promedio una tasa de interés pasiva del $6 \%$ anual. 


\section{Conclusiones}

Toda empresa tiene la libertad de elegir sus modalidades de financiación, es decir, tomar sus decisiones en función de la forma de pensar de sus fundadores, sus posibilidades, etc. En el caso de que la empresa decida prescindir de toda ayuda financiera externa y autofinancie todas sus inversiones sólo le interesará lo relativo a la política de dividendos, y con ciertas restricciones. Sin embargo, normalmente las empresas para financiarse utilizan deudas, además de recursos propios.

No siempre las empresas pueden acudir a la autofinanciación ni a los recursos de los accionistas. En ocasiones es necesario recurrir a la deuda externa.

Los motivos más corrientes son:

- Un crecimiento en la demanda de la inversión que exija la aportación de fondos necesarios para su desarrollo.

- Desinterés del accionista para aportar fondos.

- La necesidad de la empresa de tener fuentes mixtas de financiación, ya que no todas son necesariamente a plazo indefinido, como el caso de los capitales propios, sino que pueden tener un vencimiento. Dicho de otra mane$\mathrm{ra}$, los capitales propios no tienen vencimiento, pero su integración es irreversible. La deuda externa, una vez cancelada, deja de ser una carga para la empresa.

No obstante, toda empresa debe conocer cuáles son sus necesidades y limitaciones para endeudarse, estudiando antes de tomar cualquier decisión los aspectos financieros, económicos, de mercado, y la comparación del costo entre deuda externa y recursos propios.

Para el caso en análisis, podemos observar que la empresa podría efectuar su financiamiento completamente por endeudamiento, no obstante al hacer un estudio de comparación de los costos vemos que le convendría financiarse completamente con capital propio debido a la menor tasa, pero el capital con el que cuenta no es suficiente para cubrir toda la inversión, por lo que concluimos que debe utilizar ambos tipos de financiamiento. 


\section{Bibliografía}

Chan S. Parck

Ingeniería económica contemporánea. 1a. edición. Buenos Aires: Addison-Wesley/ Iberoamericana S.A., 1997.

Degarmo, Sullivan, Bontadelli, Wicks

Ingeniería económica. 10a. edición. México DF:

Prentice Hall/Hispanoamericana, S.A., 1998.

Santandreu M., Eliseo

Gestión de la financiación empresarial. 1a. edición.

Barcelona: Gestión, abril 1989.

Van Horne; James C.

Administración financiera. 2a. edición. Buenos Aires: Ediciones Contabilidad Moderna, 1973. 